\title{
The Inhibitory Activity of Human Interleukin-1 Receptor Antagonist Is Enhanced by Type II Interleukin-1 Soluble Receptor and Hindered by Type I Interleukin-1 Soluble Receptor
}

\author{
Danielle Burger, ${ }^{*}$ Rachel Chicheportiche, ${ }^{*}$ Judith G. Giri, ${ }^{\star}$ and Jean-Michel Dayer* \\ *Division of Immunology and Allergy, Hans Wilsdorf Laboratory, Department of Medicine, University Hospital, Geneva, Switzerland; \\ and ${ }^{\ddagger}$ Department of Biochemistry, Immunex Research and Development Corporation, Seattle, Washington 98101
}

\begin{abstract}
Interleukin-1 (IL-1) is a major proinflammatory cytokine produced by monocytes/macrophages. At the inflammatory site, IL-1 is a potent inducer of the production of prostaglandin $\mathbf{E}_{2}\left(\mathrm{PGE}_{2}\right)$ and metalloproteinases on fibroblast-like cells, thus triggering tissue damage. The biological activity of IL-1 is counterbalanced by two types of inhibitors: the IL-1 receptor antagonist (IL-1Ra) which competitively binds $I L-1$ receptor without inducing signal transduction; and IL-1 soluble receptors (IL-1sR) which bind IL-1 and diminish the free concentration of soluble cytokine, thus hampering its binding to the cell surface receptor. Since IL1 RR can also bind IL-1Ra, we studied the simultaneous effects of both inhibitors on the production of interstitial collagenase (C'ase) and $\mathrm{PGE}_{2}$ by human dermal fibroblasts and synovial cells stimulated by either IL-1 $\alpha$ or IL-1 $\beta$. IL-1Ra inhibited fibroblast and synovial cell stimulation by $\approx 90 \%$, with the exception of $C$ 'ase production by synovial cells which was inhibited by $\approx 55 \%$. Type I IL-1sR (IL-1sRI) preferentially inhibited IL-1 $\alpha$, whereas type II IL-1sR (IL-

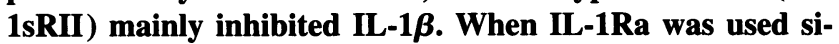
multaneously with IL-1sRI, the final inhibition was lower than that of either of the inhibitors. The simultaneous presence of IL-1Ra and IL-1sRII abolished the IL-1-induced production of $\mathrm{PGE}_{2}$ and C'ase on both dermal fibroblasts and synovial cells, demonstrating that concurrently these two inhibitors are able to abolish most of the inflammatory response. To our knowledge, this is the first example of two types of inhibitors that abolish each other's effects, one of which acts at the receptor level and the other at the ligand level, thus leaving ligand activity unimpaired. (J. Clin. Invest. 1995. 96:38-41.) Key words: interleukin-1 • interleukin-1 receptor antagonist $\bullet$ interleukin-1 soluble receptor • synovial cells $\bullet$ metalloproteinases
\end{abstract}

\section{Introduction}

The multifunctional cytokine IL-1 plays a pivotal role in inflammatory processes and induction of the immune response

Address correspondence to Dr. D. Burger, Clinical Immunology Laboratory, Division of Immunology and Allergy, University Hospital, 24 rue Micheli-du-Crest, CH-1211 Geneva 14, Switzerland. Phone: 22-372-9376; FAX: 22-372-94-18.

Received for publication 28 November 1994 and accepted in revised form 16 March 1995.

J. Clin. Invest.

(c) The American Society for Clinical Investigation, Inc. 0021-9738/95/07/0038/04 \$2.00

Volume 96 , July $1995,38-41$
$(1,2)$. Two types of IL-1 have been described, which display similar activities (3) in spite of their low amino acid sequence homology (26\%). Both IL- $1 \alpha$ and IL-1 $\beta$ act on target cells by binding to the same specific plasma membrane receptor proteins, distributed on many cell types (4). Two types of human receptors have been cloned which belong to the immunoglobulin gene superfamily, both exhibiting three extracellular immunoglobulin-like domains (5). The main structural difference between the two receptors resides in the length of their cytoplasmic domains, i.e., 213 amino acids in type I receptor and only 29 in type II (5). These two receptors do not function as an heterodimer complex, and the signal seems to be transmitted by type I receptor alone (6). Therefore, the role of type II receptor at the cell surface remains unclear. IL-1 proinflammatory effects are balanced by IL-1 receptor antagonist (IL-1Ra). ${ }^{1}$ IL-1Ra, which is structurally related to IL-1, binds IL-1 receptors competitively without inducing any biological response (for review see reference 7). In addition to IL-1Ra, IL-1 activity is balanced by soluble forms of its receptors, in analogy to other cytokines such as PDGF and TNF $(8,9)$. The soluble type II IL-1 receptor (IL-1sRII) has been detected in normal human plasma (10), synovial fluids (11), and supernatants of several human cell lines (12-14). Although soluble type I receptor (IL-1sRI) has not been clearly identified to occur naturally, a circulating factor which crossreacts weakly with anti-IL-1sRI antibodies has been detected in human normal serum (15). The IL-1 binding characteristics of this factor are different from those of IL-1sRI, since it binds IL-1Ra selectively and with high affinity (15). Therefore, since both types of IL-1 inhibitor, i.e., IL-1sR and IL-1Ra, may simultaneously be present at the inflammatory site, they may interfere with each other's activity. The aim of this study is to elucidate the simultaneous effects of IL-1Ra and IL-1sRs on the activation by IL- $1 \alpha$ and IL$1 \beta$ of normal human fibroblasts and fibroblast-like cells from inflamed synovium (synovial cells).

\section{Methods}

Materials. Dulbecco's modified Eagle's minimal essential medium (DMEM), phosphate-buffered saline, penicillin, streptomycin, L-glutamine (Gibco, Paisley, United Kingdom), and fetal calf serum (FCS) (Seromed, Biochrom KG, Berlin, Germany) were purchased from the designated suppliers. All other reagents were of analytical grade or better.

Recombinant proteins and monoclonal antibodies. Human recombinant IL-1 $\alpha$, IL-1 $\beta$, IL-1sRI, and IL-1sRII were obtained from S. Dower

1. Abbreviations used in this paper: $\mathrm{C}$ 'ase, interstitial collagenase; IL1R, IL-1 receptor; IL-1Ra, IL-1 receptor antagonist; IL-1sR, IL-1 soluble receptor; IL-1sRI, type I IL-1 soluble receptor; IL-1sRII, type II IL-1 soluble receptor. 
(Immunex Corp., Seattle, WA $(5,16)$. IL-1Ra was a generous gift from Dr. R. Thompson (Synergen, Boulder, CO). Antibodies to interstitial collagenase (C'ase) and C'ase standard for ELISA were generously provided by Dr. H. G. Welgus (Division of Dermatology, Jewish Hospital at Washington University Medical Center, St. Louis, MO).

Cells. Human dermal fibroblasts and synovial fibroblast-like cells (synovial cells) were isolated by protease treatment of foreskin and surgical synovectomy specimens from rheumatoid arthritis or osteoarthritis patients, respectively $(17,18)$. Dermal fibroblasts and synovial cells were cultured in DMEM supplemented with $10 \%$ FCS, $50 \mathrm{IU} / \mathrm{ml}$ penicillin, $50 \mu \mathrm{g} / \mathrm{ml}$ streptomycin, and $2 \mathrm{mM} \mathrm{L}$-glutamine at $37^{\circ} \mathrm{C}$ in $5 \% \mathrm{CO}_{2}$. The cells were seeded into 96-well flat-bottom plates $(2$ $\times 10^{4}$ cells/well) and maintained for $48 \mathrm{~h}$ in complete DMEM before testing (see below).

To ensure that $\mathrm{IL}-1 \alpha$ and $\mathrm{IL}-1 \beta$ biological activity was induced on cells due to the binding to type I receptor, the production of $\mathrm{PGE}_{2}$ was measured in fibroblast supernatants cultured in the presence or absence of monoclonal antibodies directed against IL-1RI or IL-1RII. The monoclonal antibody, which specifically blocks the binding of IL-1 to IL1RI, inhibited $\mathrm{PGE}_{2}$ and $\mathrm{C}^{\prime}$ ase production by dermal fibroblasts in a dose-dependent manner, i.e., $50-60 \%$ inhibition at $10 \mu \mathrm{g} / \mathrm{ml}$ and $>95 \%$ at $100 \mu \mathrm{g} / \mathrm{ml}$. In contrast, the monoclonal antibody directed against IL$1 \mathrm{RII}$ did not affect $\mathrm{PGE}_{2}$ production in accordance with previous binding studies (6). Although a lower inhibition by anti-IL-1RI was observed, comparable results were obtained with synovial cells, indicating that signal transduction in both types of cells was induced via the binding of IL-1 to IL-1RI.

Inhibition of IL- $1 \alpha$ and IL-1 $\beta$ biological activities by IL-1 inhibitors. To study the simultaneous effect of the two types of IL-1 inhibitors (i.e., IL-1sR and IL-1Ra), the cells were stimulated by either IL-1 $\alpha$ or IL-1 $\beta$ in the presence or absence of inhibitors. To optimize the inhibition, IL- $1 \alpha$ or IL- $1 \beta\left(125 \mathrm{pg} / \mathrm{ml}\right.$, i.e., $\left.\approx 7 \times 10^{-12} \mathrm{M}\right)$ was preincubated in the presence or absence of either IL-1sR $(625 \mathrm{ng} / \mathrm{ml}$, i.e., $\approx 1$ $\times 10^{-8} \mathrm{M}$ IL-1sRI and $\left.\approx 1.5 \times 10^{-8} \mathrm{M} \mathrm{IL}-1 \mathrm{sRII}\right)$ or IL-1Ra $(125 \mathrm{ng} /$ $\mathrm{ml}$, i.e., $\approx 7 \times 10^{-9} \mathrm{M}$ ) or both for $1 \mathrm{~h}$ at $37^{\circ} \mathrm{C}$ in complete DMEM before addition to the cells. After $72 \mathrm{~h}, \mathrm{C}^{\prime}$ ase and $\mathrm{PGE}_{2}$ were measured in the culture supernatants. These experiments were repeated at least four times. The results were unchanged when IL-1Ra was preincubated with the cells for $1 \mathrm{~h}$ at $37^{\circ} \mathrm{C}$ while $\mathrm{IL}-1$ and $\mathrm{IL}-1 \mathrm{sR}$ were preincubated together before being added to the cells. In another set of experiments, the effects of both IL-1sRI and IL-1sRII on the inhibitory activity of IL-1Ra were examined under two different preincubation conditions: (a) the inhibitors were preincubated for $1 \mathrm{~h}$ at $37^{\circ} \mathrm{C}$ and then for another $1 \mathrm{~h}$ with the cells before the addition of $\mathrm{IL}-1$; and $(b)$ the inhibitors were preincubated together for $1 \mathrm{~h}$ at $37^{\circ} \mathrm{C}$ and then for another hour with IL-1 before being added to the cells. After $72 \mathrm{~h}$ of incubation, the supernatants were analyzed as described above.

Interstitial collagenase (C'ase) and PGE 2 . C'ase was measured by ELISA, using specific rabbit polyclonal antisera (19) with a detection limit of $10 \mathrm{ng} / \mathrm{ml}$. $\mathrm{PGE}_{2}$ was measured by a double antibody radioimmunoassay as described previously (17), using an antiserum to $\mathrm{PGE}_{2}$ provided by Dr. M. Seitz (Department of Rheumatology, University Hospital, Bern, Switzerland). The detection limit for $\mathrm{PGE}_{2}$ was $0.5 \mathrm{ng} / \mathrm{ml}$. All measurements were carried out in triplicates.

\section{Results}

Since normal fibroblasts and fibroblast-like cells from inflammatory tissue display different characteristics, dermal fibroblasts and fibroblast-like cells from synovial tissue (synovial cells ) were used to study the simultaneous biological effects of the two types of IL-1 inhibitors, i.e., IL-1 soluble receptors and IL-1Ra. Although the production of $\mathrm{PGE}_{2}$ and C'ase varied considerably from one experiment to the other, both dermal fibroblasts and synovial cells displayed basal production of $\mathrm{PGE}_{2}$ and $\mathrm{C}$ 'ase. Dermal fibroblasts produced $15.2 \pm 6.9 \mathrm{ng} /$

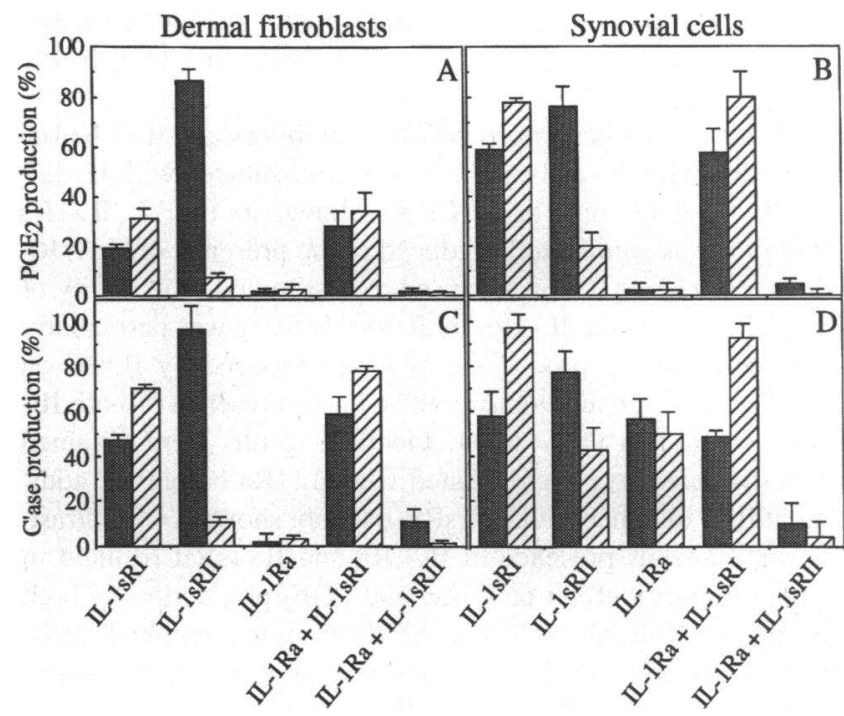

Figure 1. Inhibition of $\mathrm{PGE}_{2}$ and $\mathrm{C}$ 'ase production on human fibroblasts stimulated by either IL-1sRs or IL-1Ra or both types of inhibitor. The inhibition of fibroblast stimulation was estimated by measuring the production of $\mathrm{PGE}_{2}(A$ and $B)$ and $C^{\prime}$ ase $(C$ and $D)$ and expressed as percentage of total production ( $100 \%$ was the production obtained in the absence of inhibitor). Dermal fibroblasts $(A$ and $C$ ) and synovial cells $(B$ and $D$ ) were stimulated by $\mathrm{IL}-1 \alpha$ (dark bars) or IL-1 $\beta$ (striped bars) in the presence of the designated inhibitors, as described in Methods. Results represent the average value of four separate experiments (mean \pm SEM).

$\mathrm{ml} \mathrm{PGE}_{2}$ and $0.5 \pm 0.2 \mu \mathrm{g} / \mathrm{ml} \mathrm{C'ase.} \mathrm{Synovial} \mathrm{cells} \mathrm{produced}$ $13.4 \pm 20.0 \mathrm{ng} / \mathrm{ml} \mathrm{PGE} 2$ and $0.6 \pm 0.5 \mu \mathrm{g} / \mathrm{ml} \mathrm{C'ase.} \mathrm{On} \mathrm{dermal}$ fibroblasts, $\mathrm{PGE}_{2}$ production was increased $\approx 14$ - and 10 -fold by $\mathrm{IL}-1 \alpha$ and $\mathrm{IL}-1 \beta$, respectively, and C'ase production, 3.8and 3.6-fold, whereas on synovial cells, IL- $1 \alpha$ and IL-1 $\beta$ enhanced 4.6- and 4.1-fold the basal production of $\mathrm{PGE}_{2}$, and 3.6and 3.5 -fold that of $C$ 'ase, respectively. In both cell types, $\mathrm{IL}-1 \alpha$ was slightly more efficient than $\mathrm{IL}-1 \beta$ in inducing the production of $\mathrm{PGE}_{2}$ and C'ase.

Before assessing the simultaneous effect of IL-1Ra and soluble receptors on fibroblasts stimulated with $\mathrm{IL}-1$, the effects of each inhibitor were established. To ensure optimal inhibition by $\mathrm{IL}-1 \mathrm{Ra}$ and $\mathrm{IL}-1 \mathrm{sRs}$, concentrations $\approx 1,000$ times those of IL-1 $\alpha$ and IL-1 $\beta$ (7.4 pM) were used, i.e., IL-1Ra at $6.9 \mathrm{nM}$, IL-1sRI at $10.4 \mathrm{nM}$, and IL-1sRII at $14.5 \mathrm{nM}$. As shown in Fig. 1 , IL-1sRI exhibited a higher inhibitory effect when the cells were stimulated with IL- $1 \alpha$ than with IL- $1 \beta$. In contrast, IL1sRII hardly interfered with IL-1 $\alpha$ stimulation (inhibition $\approx 25 \%$ ) but inhibited IL- $1 \beta$ activity to a marked extent. Of interest, the inhibition observed with IL-1sRI was higher on dermal fibroblasts than on synovial cells, suggesting that a higher concentration of free IL-1 was required to activate dermal fibroblasts than synovial cells. Similarly, IL-1sRII was less efficient at inhibiting synovial cells than dermal fibroblasts stimulated by $\mathrm{IL}-1 \beta$, confirming that synovial cells required lower cytokine concentration for activation. IL-1Ra displayed high inhibitory activity on dermal fibroblasts, inhibiting $>95 \%$ of the induced $\mathrm{PGE}_{2}$ and $\mathrm{C}^{\prime}$ ase production (Fig. 1, $A$ and $B$ ). IL$1 \mathrm{Ra}$ also abolished the induced production of $\mathrm{PGE}_{2}$ on synovial cells (Fig. $1 \mathrm{C}$ ), whereas it inhibited the production of C'ase by only 43 and $50 \%$ when using $I L-1 \alpha$ and IL-1 $\beta$ as a stimulus, respectively (Fig. $1 D$ ). This latter result suggests that the occu- 
pancy of a very low number of membrane receptors by IL-1 $\alpha$ or $\mathrm{IL}-1 \beta$ was required to induce $C$ 'ase production by synovial cells.

To optimize interactions between inhibitors and IL-1 before incubation with the cells, IL-1Ra was preincubated with IL-1sR and $\mathrm{IL}-1$ for $60 \mathrm{~min}$ at $37^{\circ} \mathrm{C}$. As shown in Fig. 1, IL-1Ra inhibition was significantly reduced in the presence of IL-1sRI, whether IL- $1 \alpha$ or IL- $1 \beta$ was used as a stimulus. The ability of IL-1sRI to revert the IL-1Ra inhibitory activity was particularly pronounced in the production of C'ase induced by $\mathrm{IL}-1 \beta$ on synovial cells, amounting to $>90 \%$ in the presence of both IL1sRI and IL-1Ra (Fig. 1 D). Identical results were obtained when the cells were preincubated with IL-1Ra before the addition of IL-1 together with IL-1sRI (data not shown). In contrast, the simultaneous presence of IL-1Ra and IL-1sRII resulted in a high inhibitory effect on C'ase and $\mathrm{PGE}_{2}$ production by both cell types. Noticeably, C'ase production by synovial cells, hardly inhibited by IL-1Ra, was virtually abolished in the simultaneous presence of IL-1Ra and IL-1sRII (Fig. 1 D).

To assess the simultaneous effects of both soluble receptors, experiments were carried out by incubating synovial cells in the presence of both IL-1sRI and IL-1sRII by using two different preincubation procedures: $(a)$ the inhibitors were preincubated for $1 \mathrm{~h}$ at $37^{\circ} \mathrm{C}$ and then for another hour with the cells before the addition of IL-1 (Fig. $2 A$ ); and $(b)$ the inhibitors were preincubated together for $1 \mathrm{~h}$ at $37^{\circ} \mathrm{C}$ and then for another hour with IL-1 before being added to the cells (Fig. 2 B). After 72 $\mathrm{h}$ of incubation, the supernatants were analyzed as described above. The representative experiment of Fig. $2 \mathrm{~A}$ shows that, when IL-1sRI and IL-1sRII were present simultaneously, additive inhibition was obtained, i.e., $\mathrm{PGE}_{2}$ production induced by IL- $1 \alpha$ was inhibited to levels obtained with IL-1sRI alone and $\mathrm{PGE}_{2}$ production induced by $\mathrm{IL}-1 \beta$ was inhibited to levels obtained with IL-1sRII alone. This confirms the results of Fig. 1 which demonstrated that IL-1sRI mainly inhibited IL- $1 \alpha$, and IL-1sRII mainly inhibited IL- $1 \beta$. When IL-1sRI and IL-1sRII were added together with IL-1Ra, the inhibition of $\mathrm{PGE}_{2}$ production observed in the presence of IL-1Ra or IL-1Ra and IL1 sRII was reverted, particularly when IL-1 $\alpha$ was the stimulus (Fig. $2 A$ ). Similar results were obtained by using the second preincubation procedure (Fig. $2 B$ ), demonstrating that the interactions between IL-1, IL-1sRs, and the cellular receptors are reversible and that they depend on the respective affinities of IL- $1 \alpha$, IL- $1 \beta$, and IL-1Ra for their ligands. Together, the experiments of Figs. 1 and 2 suggest that IL-1sRI and IL-1Ra dulled their respective inhibitory activity.

\section{Discussion}

The enhancement of the production of $\mathrm{PGE}_{2}$ (i.e., a potent local proinflammatory factor) and C'ase (i.e., a metalloproteinase which plays a major role in extracellular matrix destruction) by IL-1 stimulation of fibroblasts, is an important process in the inflammatory response and the persistence of inflammation in chronic inflammatory diseases. In this study, two types of stroma cells have been used to examine the balance of IL-1 stimulation by IL-1Ra or IL-1sR. The comparison of these two types of cells shows that synovial cells are slightly modulated by IL-1 stimulation. The production of $\mathrm{PGE}_{2}$ and C'ase was enhanced $\approx 4$-fold on synovial cells, whereas on dermal fibroblasts it was enhanced $\approx 10$ - and 4-fold, respectively. Furthermore, the inhibition obtained with either IL-1sR or IL-1Ra was

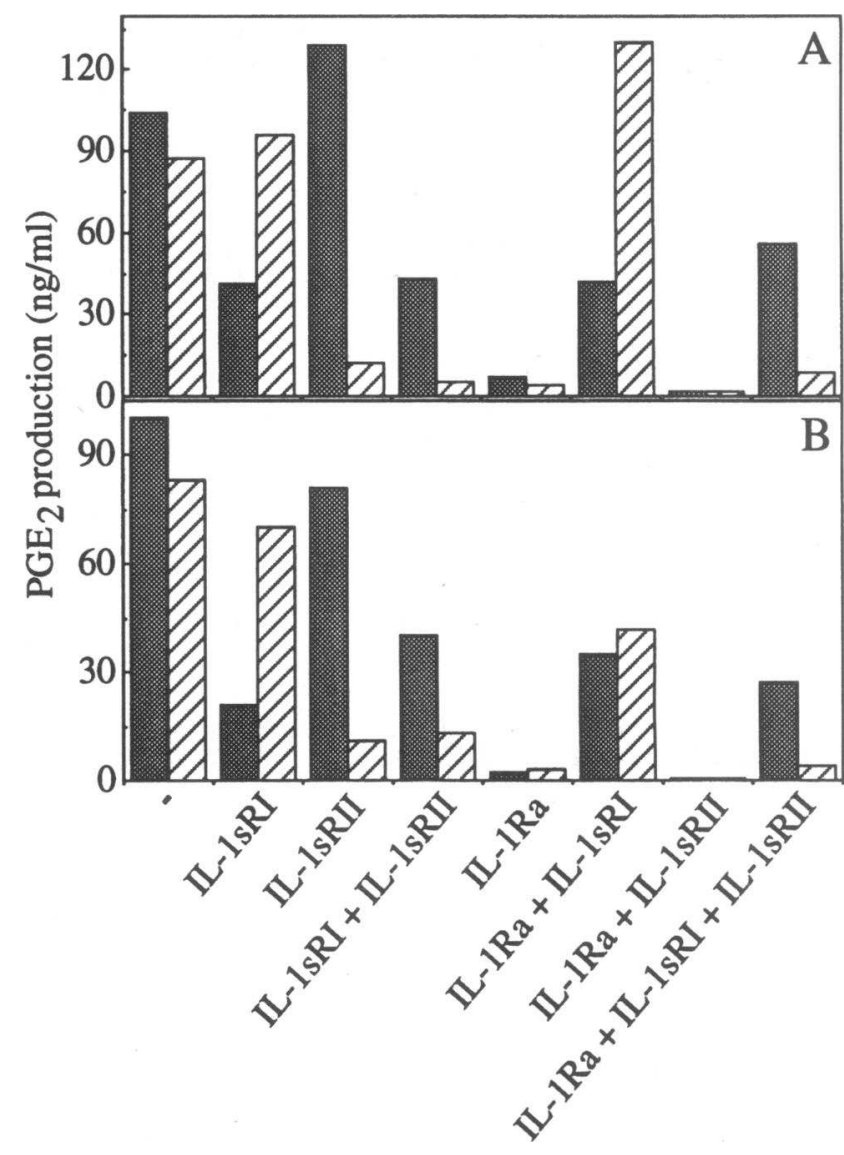

Figure 2. Inhibition of $\mathrm{PGE}_{2}$ on human synovial cells stimulated by $\mathrm{IL}$ 1sRI, IL-1sRII, and IL-1Ra. Synovial cells were stimulated by IL-1 $\alpha$ (dark bars) or IL-1 $\beta$ (striped bars) in the absence $(-$ ) or presence of the indicated inhibitors. $(A)$ The inhibitors were preincubated for $1 \mathrm{~h}$ at $37^{\circ} \mathrm{C}$ and then for another hour with the cells before the addition of $\mathrm{IL}-1$; and $(B)$ the inhibitors were preincubated together for $1 \mathrm{~h}$ at $37^{\circ} \mathrm{C}$ and then for another hour with IL-1 before being added to the cells. After $72 \mathrm{~h}$ of incubation, the supernatants were analyzed for the presence of $\mathrm{PGE}_{2}$.

generally less pronounced on synovial cells than on dermal fibroblasts (Fig. 1); noticeably, the inhibition of C'ase production by IL-1Ra on synovial cells was only $\approx 45 \%$. This suggests that inflammatory stromal cells display a higher sensitivity to IL-1 than do normal fibroblasts. Similarly, human osteoarthritic chondrocytes also display a higher sensitivity to IL-1 than normal chondrocytes (20), due to a higher density of IL-1RI on the inflammatory cells. Whether the higher sensitivity of synovial cells to IL-1 is due to a change in IL-1RI affinity or to a greater receptor density on the cell surface remains to be determined.

The salient result described in this paper is the decrease of the inhibitory activity of IL-1Ra prompted by the simultaneous presence of IL-1sRI, whereas the simultaneous presence of both IL-1Ra and IL-1sRII does not affect (Fig. $1, A-C$ ) or even enhance the inhibition (Fig. $1 D$ ). This is the first observation of the dulling effect of IL-1sRI on the biological inhibitory activity of IL-1Ra in the presence or absence of IL-1sRII. To our knowledge, this is the first example of two types of inhibitors that abolish each other's effects, one of which acts at the receptor level and the other at the ligand level, thus leaving 
ligand activity unimpaired. These results suggest that $\mathrm{IL}-1$ sRI displays a higher affinity for IL-1Ra than IL-1sRII, consistent with the binding data obtained with $\operatorname{COS}$ cells transfected with either human IL-1RI or IL-1RII (5). Since identical results are obtained when the cells are preincubated with IL-1Ra before the addition of IL-1sRI and IL-1, our results strongly suggest that human IL-1sRI displays higher affinity for IL-1Ra than membrane-bound IL-1RI. In agreement with this finding, recent results by Svenson et al. (15) have shown that human IL-1sRI binds IL-1Ra with a $K_{\mathrm{d}}$ of $14 \mathrm{pM}$, i.e., an affinity which is 200 times that of membrane-bound IL-1RI (5). Besides, our results demonstrate that IL-1sRI inhibits preferentially IL-1 $\alpha$, whereas IL-1sRII inhibits preferentially IL-1 $\beta$. Together with the data of McMahan et al. (5), this suggests that IL-1Ra is, by virtue of its specificity toward IL-1RI, i.e., the receptor which transduces the signal, optimized to interfere with IL-1 agonist signal transduction, and not as strongly directed toward IL-1RII. Furthermore, IL-1RII preferentially binds $I L-1 \beta(5)$, potentially limiting the effect of IL- $1 \beta$ on IL-1RI for which it does not display as high an affinity as does IL- $1 \alpha$. Such a mechanism might explain both how cells can respond to IL-1 and how IL1 Ra can function as a competitive inhibitor of signal transduction even when subjected to a large number of IL-1RII or IL1sRII, which might otherwise be expected to severely interfere with IL-1Ra inhibition.

Endogenous IL-1Ra production plays an important part in disease outcome since neutralizing antibodies to IL-1Ra worsen disease $(21,22)$. Therefore, because of their ability to interfere with inflammatory mechanisms, IL-1Ra as well as IL-1sRI have been used individually as therapeutic agents in various animal models with some efficiency (for review see references 7 and 23). In humans, however, considering the results described in this paper and the binding studies of Svenson et al. (15), the use of IL-1sRI does not seem to be advisable, since it counters the inhibitory effect of IL-1Ra. In contrast, we hypothesize that the simultaneous use of both IL-1Ra and IL-1sRII might be mostly beneficial.

\section{Acknowledgments}

The authors would like to thank Mrs. M.-T. Kauffman for skillful technical assistance.

This work was supported by the Swiss National Science Foundation (grant 31-33786-92), the Swiss Cancer League, and the Swiss Federal Commission for Rheumatic Diseases.

\section{References}

1. Arend, W. P., and J. M. Dayer. 1990. Cytokines and cytokine inhibitors or antagonists in rheumatoid arthritis. Arthritis Rheum. 33:305-315.

2. Opdenakker, G., and J. van Damme. 1992. Cytokine and proteases in invasive processes: molecular similarities between inflammation and cancer. $\mathrm{Cy}$ tokine. 4:251-258.
3. Burke, F., M. S. Naylor, B. Davies, and F. Balkwill. 1993. The cytokine wall chart. Immunol. Today. 14:165-168.

4. Dower, S. K., and D. L. Urdal. 1987. The interleukin-1 receptor. Immunol. Today. 8:46-51.

5. McMahan, C. J., J. Slack, D. Cosman, S. D. Lupton, L. L. Brunton, C. E. Grubin, J. M. Wignall, N. A. Jenkins, C. I. Brannan, N. G. Copeland, et al. 1991. A novel IL-1 receptor, cloned from B cells by mammalian expression, is expressed in many cell types. EMBO (Eur. Mol. Biol. Organ.) J. 10:2821-2832.

6. Slack, J., C. J. McMahan, S. Waugh, K. Schooley, M. K. Spriggs, J. E. Sims, and S. K. Dower. 1993. Independent binding of interleukin- $1 \alpha$ and interleukin-1 $\beta$ to type I and type II interleukin-1 receptors. J. Biol. Chem. 268:2513-2524.

7. Arend, W. P., and J.-M. Dayer. 1994. Naturally occuring inhibitors of cytokines. In Immunopharmacology of Joints and Connective Tissue. M. E. Davies and J. T. Dingle, editors. Academic Press, London. 129-149.

8. Tiesman, J., and C. Hart. 1993. Identification of a soluble receptor for platelet-derived growth factor in cell-conditioned medium and human plasma. $J$. Biol. Chem. 268:9621-9628.

9. Rothe, J., G. Gehr, H. Loetscher, and W. Lesslauer. 1992. Tumor necrosis factor receptors-structure and function. Immunol. Res. 11:81-90.

10. Eastgate, J. A., J. A. Symons, and G. W. Duff. 1990. Identification of an interleukin-1 beta binding protein in human plasma. FEBS (Fed. Eur. Biochem. Soc.) Lett. 260:213-216.

11. Symons, J. A., J. A. Eastgate, and G. W. Duff. 1990. A soluble binding protein specific for interleukin $1 \beta$ is produced by activated mononuclear cells. Cytokine. 2:190-198.

12. Symons, J. A., J. A. Eastgate, and G. W. Duff. 1991. Purification and characterization of a novel soluble receptor for interleukin 1. J. Exp. Med. 174:1251-1254.

13. Symons, J. A., and G. W. Duff. 1990. A soluble form of the interleukin1 receptor produced by a human B cell line. FEBS (Fed. Eur. Biochem. Soc.) Lett. 272:133-136.

14. Giri, J. G., R. C. Newton, and R. Horuk. 1990. Identification of soluble interleukin-1 binding protein in cell-free supernatants. Evidence for soluble interleukin-1 receptor. J. Biol. Chem. 265:17416-17419.

15. Svenson, M., M. B. Hansen, P. Heegaard, K. Abell, and K. Bendtzen. 1993. Specific binding of interleukin-1 (IL-1) beta and IL-1 receptor antagonist (IL-1ra) to human serum. High-affinity binding of IL-1 ra to soluble IL-1 receptor type-I. Cytokine. 5:427-435.

16. Sims, J. E., R. B. Acres, C. E. Grubin, C. J. McMahan, J. M. Wignall, C. J. March, and S. K. Dower. 1989. Cloning the interleukin 1 receptor from human T cells. Proc. Natl. Acad. Sci. USA. 86:8946-8950.

17. Seckinger, P., M.-T. Kaufmann, and J.-M. Dayer. 1990. An interleukin 1 inhibitor affects both cell-associated interleukin 1-induced $\mathrm{T}$ cell proliferation and $\mathrm{PGE}_{2} /$ collagenase production by human dermal fibroblasts and synovial cells. Immunobiology. 180:316-327.

18. Dayer, J.-M., J. BrÄard, L. Chess, and S. M. Krane. 1979. Participation of monocyte-macrophages and lymphocytes in the production of a factor that stimulates collagenase and prostaglandin release by rheumatoid synovial cells. $J$. Clin. Invest. 64:1386-1392.

19. Lacraz, S., L. Nicod, B. Galve-de-Rochemonteix, C. Baumberger, J. M. Dayer, and H. G. Welgus. 1992. Suppression of metalloproteinase biosynthesis in human alveolar macrophages by interleukin-4. J. Clin. Immunol. 90:382-388.

20. Martel-Pelletier, J., R. McCollum, J. DiBattista, M. P. Faure, J. A. Chin, S. Fournier, M. Sarfati, and J. P. Pelletier. 1992. The interleukin-1 receptor in normal and osteoarthritic human articular chondrocytes. Identification as the type I receptor and analysis of binding kinetics and biologic function. Arthritis Rheum. 35:530-540.

21. Chensue, S. W., M. Bienkowski, T. E. Eessalu, K. S. Warmington, S. D. Hershey, N. W. Lukas, and S. L. Kunkel. 1993. Endogenous IL-1 receptor antagonist protein (IRAP) regulates schistosome egg granuloma formation and the regional lymphoid response. J. Immunol. 151:3654-3662.

22. Ferretti, M., V. Casini-Raggi, T. T. Pizarro, S. P. Eisenberg, C. C. Nast, and F. Cominelli. 1994. Neutralization of endogenous IL-1 receptor antagonist exacerbates and prolongs inflammation in rabbit immune colitis. J. Clin. Invest. 94:449-453.

23. Arend, W. P. 1993. Interleukin-1 receptor antagonist. Adv. Immunol. 54:167-227. 